\title{
Teorias da linguística cognitiva para pensar a categorização no âmbito da Ciência da Informação
}

\section{Cognitive linguistics theories to discuss categorization in Information Sciences}

\author{
Luciana Monteiro KREBS ${ }^{1}$ \\ Rita do Carmo Ferreira LAIPELT1
}

\begin{abstract}
Resumo
Discorre-se sobre fenômenos descritos pela Linguística Cognitiva, estabelecendo relações com a Ciência da Informação, tendo a categorização como fio condutor temático da discussão. A categorização é abordada pela perspectiva da Linguística Cognitiva e cotejada com as demais abordagens linguísticas, com o objetivo de contribuir para a pesquisa na área de organização do conhecimento. Abordam-se os conceitos de análise componencial sêmica, conhecimento dicionarístico e enciclopédico, para depois se trabalharem teorias da Linguística Cognitiva, como semelhanças familiares, Semântica de Frames, categorias radiais, teoria dos protótipos e, por fim, barreiras categoriais fluidas. Conclui-se que a categorização se dá através de complexos processos que refletem aspectos experimentais, imaginativos e ecológicos da mente, colocando em suspenso a ideia de que as categorias possuam limites claros e rígidos. A interpretação de conceitos e, consequentemente, a categorização dependem do contexto de aplicação e, portanto, não são universais. Este artigo contribui para a discussão vigente a respeito da problemática da interoperabilidade de Simple Knowledge Organization System a partir da reflexão sobre essas questões.
\end{abstract}

Palavras-chave: Categorização. Ciência da Informação. Linguística cognitiva. Organização do conhecimento.

\begin{abstract}
This paper discusses phenomena of interest of Cognitive Linguistics, connecting the perspective of Information Science and other linguistic approaches, and having categorization as a guide in the discussion. It addresses the concepts of semic componential analysis and dictionary and encyclopedic knowledge to then deal with Cognitive Linguistics theories such as family resemblances, Frame semantics, radial categories, prototypes theory, and finally fluid categorical barriers. The conclusions are that the categorization happens through complex processes that reflect experimental, imaginative and ecological aspects of the human mind, refuting the idea that the categories have clear and strict limits.
\end{abstract}

Keywords: Categorization. Information Science. Cognitive Linguistics. Organization of knowledge.

\section{Introdução}

A organização do conhecimento é um complexo processo que visa, entre outras coisas, à recuperação da informação, e envolve um esforço cognitivo do profissional que o realiza, para entender não apenas o conteúdo

\footnotetext{
1 Universidade Federal do Rio Grande do Sul, Faculdade de Biblioteconomia e Comunicação, Departamento de Ciências da Informação. R. Ramiro Barcelos, 2705, Santana, 90035-007, Porto Alegre, RS, Brasil. Correspondência para/Correspondence to: R.C.F. LAIPELT. E-mail: <ritacarmo@yahoo.com.br>.

Recebido em 13 de janeiro de 2017, versão final reapresentada em 19 de março de 2017 e aprovado em 21 de abril de 2017.

Como citar este artigo/How to cite this article

Krebs, L. M.; Laipelt, R. C. F. Teorias da linguística cognitiva para pensar a categorização no âmbito da ciência da informação. Transinformação, v. 30, n. 1, p. 81-93, 2018. https://doi.org/10.1590/2318-08892018000100007
} 
da obra a ser indexada, como também as possíveis necessidades informacionais dos usuários da unidade de informação. Exige, sobretudo, compreensão dos principais itens de valor para a comunidade usuária da informação. Nesse contexto, caracteriza-se a importância da Linguística (em especial, a Linguística Cognitiva) em uma discussão que tenha como foco o entendimento da categorização na Ciência da Informação.

Bräscher e Café $(2008$, p.8) definem a organização do conhecimento como:

[...] o processo de modelagem do conhecimento que visa a construção de representações do conhecimento. Esse processo tem por base a análise do conceito e de suas características para o estabelecimento da posição que cada conceito ocupa num determinado domínio, bem como das suas relações com os demais conceitos que compõem esse sistema nocional.

Nesse processo, é relevante que o bibliotecário tenha acesso a conhecimentos desenvolvidos na área da Linguística Cognitiva, os quais podem ser úteis durante a indexação, para apreender (tanto quanto se pôde descobrir até o momento) sobre a maneira como ocorre a categorização na cognição humana. Este trabalho visa apresentar algumas das principais teorias que abordam a categorização pela ótica da Linguística Cognitiva.

Procurou-se demonstrar as principais características de cada teoria e suas contribuições para a elaboração de Sistemas de Organização de Conhecimento (Simple Knowledge Organization System - SKOS), como tesauros e ontologias, enquanto sistemas essencialmente conceituais. Nesse sentido, para o aperfeiçoamento e/ou elaboração de SKOS acredita-se que é necessário contemplar aspectos linguísticos característicos da língua em uso.

A partir das características das teorias aqui expostas, é possível perceber uma convergência de interesses entre essas teorias e a prática de organização do conhecimento, especificamente em relação à recuperação da informação. No âmbito da Ciência da Informação, são recorrentes as pesquisas e debates que visam ao aperfeiçoamento dos sistemas de recuperação da informação, tendo em vista que uma de suas principais falhas, de um modo geral, está na divergência entre a linguagem dos usuários e a linguagem dos responsáveis por sua organização. Logo, teorias que contribuam para a compreensão do universo dos falantes de um determinado domínio certamente são relevantes no processo de elaboração de tesauros.

Uma diferença teórica relevante entre a Semântica tradicional (parte da tríade clássica: sintaxe, semântica e pragmática) e a Linguística Cognitiva é o papel da cognição na representação que se faz do mundo. Assim, muda a perspectiva de equivalência entre signo e referente no mundo, como propõe a visão tradicional, para uma abordagem de interpretações que as pessoas fazem das coisas e dos conceitos que constroem a partir disso; "O significado de uma expressão linguística não reflete diretamente a relação entre 'palavra' e 'mundo', mas é sempre mediado por processos inerentes à cognição humana" (Ferrari, 2010, p.151).

Para Fiorin (2002, p.56), "[...] a atividade linguística é uma atividade simbólica, o que significa que as palavras criam conceitos e esses conceitos ordenam a realidade, categorizam o mundo". Citam-se também Silva e Batoréo (2010, p.233):

Um dos princípios essenciais em Linguística Cognitiva diz que o significado é conceptualização. Um processo de conceptualização consiste numa determinada perspectivação do conceptualizador relativamente a uma entidade ou situação. Quer isto dizer que a conceptualização envolvida no significado de uma expressão lexical ou gramatical não pode ser caracterizada somente em termos das propriedades do objecto de conceptualização, mas tem que necessariamente ter em conta o sujeito de conceptualização.

É preciso ter em conta que não se trata aqui do corte semântico que Saussure propôs, evidenciando diferenças entre línguas por meio do conceito de valor. Há diferenças de interpretação até mesmo entre as pessoas que falam a mesma língua, porque a interpretação está intimamente ligada com a experiência de vida de cada indivíduo, além de aspectos culturais. Em Linguística Cognitiva, costuma-se designar o modo e os modos alternativos de conceitualizar determinada situação pela expressão "perspectivação conceitual" (tradução proposta por Silva e Batoréo para o termo inglês "construal") (Silva; Batoréo, 2010). 
Segundo Fiorin (2002, p.56), "[...] as palavras formam um sistema autônomo que independe do que elas nomeiam, o que significa que cada língua pode categorizar o mundo de forma diversa". Assim, pode-se afirmar que nenhum ser no mundo pertence a uma determinada categoria, "[...] os homens é que criam as categorias e põem nelas os seres" (Fiorin, 2002, p.57).

A seguir discorre-se sobre alguns fenômenos de interesse da Linguística Cognitiva que podem ser úteis no processo de organização do conhecimento, estabelecendo relações entre a perspectiva adotada por ela e as demais abordagens linguísticas, tendo a categorização como guia temático da discussão.

\section{Premissas da Linguística Cognitiva e contextualização histórico-teórica}

A Linguística Cognitiva (LC) é um paradigma teórico da Linguística que surgiu nos anos 1980, reunindo uma série de teorias a respeito da linguagem em torno de hipóteses centrais compartilhadas por diversos estudiosos, com foco especial na construção do significado. Os teóricos George Lakoff, Ronald Langacker, Leonard Talmy, Charles Fillmore e Gilles Fauconnier destacam-se nessa área do conhecimento interessada em dar conta de relações entre sintaxe e semântica, investigando especialmente as relações entre forma e significado na teoria linguística.

O posicionamento inclusivo da LC tem início na abrangência geral da linguagem e reflete-se em teorias que serão tratadas a seguir, como o conhecimento enciclopédico. Em primeiro lugar, a LC defende a não-modularização da mente, além dos compromissos teóricos de interdisciplinaridade e busca de generalização. Para Silva (1997, p.2), a LC não aceita, dentre outros, os seguintes postulados:

[...] a separação entre conhecimento 'semântico' (ou 'linguístico') e conhecimento 'enciclopédico' (ou 'extralinguístico'), fundamentada no postulado da existência de um nível estrutural ou sistémico de significação linguística (relativamente ao qual se considera que se podem e devem definir e analisar as categorias linguísticas), distinto do nível em que o conhecimento do mundo está associado às formas linguísticas; o postulado saussureano da arbitrariedade do signo linguístico; a afirmação da discrição e homogeneidade das categorias linguísticas; a ideia de que a linguagem é gerada por regras lógicas e por traços semânticos 'objectivos'; a tese chomskyana da autonomia e da não-motivação semântica e conceptual da sintaxe.

A não-modularidade da mente é um ponto fundamental da abordagem da LC. O cognitivismo clássico de Chomsky preconiza a capacidade inata da linguagem humana desenvolvida em um módulo exclusivo para esse fim na mente do falante. A Linguística Cognitiva, no entanto, aposta em uma perspectiva não modular, em que princípios cognitivos gerais são compartilhados pela linguagem e outras capacidades cognitivas, prevendo a interação de estrutura linguística e conteúdo conceptual. Esse conceito é o que dá embasamento para o realismo corporificado (inicialmente chamado de experiencialismo), de autoria de Lakoff e Johnson em 1980, através do qual se acredita que a natureza peculiar do corpo humano modela suas possibilidades de conceptualização e categorização, determinando não apenas que os indivíduos categorizem, mas também que tipo de categorias terão e a estrutura das mesmas (Ferrari, 2001).

O compromisso interdisciplinar preconiza que os princípios gerais da LC devam ser compatíveis com o cabedal de conhecimentos disponíveis sobre a mente e o cérebro em disciplinas afins. Assim, acredita-se que há princípios cognitivos gerais (e não apenas princípios especificamente linguísticos) atuantes na organização da linguagem. Dessa forma, a LC "[...] assume o compromisso de compatibilizar suas hipóteses com os resultados de pesquisas sobre a mente e o cérebro realizadas por outras disciplinas, principalmente na área das Ciências Cognitivas (Filosofia, Psicologia, Inteligência Artificial e Neurociências)" (Ferrari, 2001, p.26).

Já na busca por generalização a LC assume que os diferentes módulos da linguagem (fonologia, morfologia, sintaxe, semântica e pragmática) compartilham traços fundamentais de organização. Dessa forma, os mesmos princípios gerais atuam em todos os níveis de análise linguística e, a partir daí, fenômenos podem ser estudados de forma mais abrangente e completa. 
O compromisso interdisciplinar trouxe repercussões no estudo de categorização sob influência da Psicologia Cognitiva. Classes de palavras (nomes, verbos, adjetivos etc.) eram normalmente concebidas como bem delimitadas, já que suas características autorizam sua inclusão dentro dos limites categoriais, possibilitando sua classificação segundo seu comportamento morfológico, distribucional e semântico. Na Psicologia Cognitiva, entretanto, os contornos categoriais são pouco rígidos, evidenciando membros "mais centrais" (que apresentam todos os traços definidores da categoria) e outros "mais periféricos" (que apresentam alguns, mas não todos os traços definidores). Na seção "Categorias radiais" deste ensaio serão exploradas as categorias radiais, cujos membros se afastam, em maior ou menor grau, do centro categorial. Mas, antes de adiantar tais questões, convida-se o leitor a revisar o conceito de categorização.

\section{Categorização}

A maneira como se formam as categorias conceituais é um tema de extrema relevância para a Linguística. A categorização é o processo por meio do qual se agrupam entidades semelhantes (objetos, pessoas, lugares etc.) em classes específicas (Ferrari, 2011). A categorização é um fator básico para a sobrevivência: enxergar uma árvore como uma categoria e não como um indivíduo único é uma das capacidades que viabilizam a comunicação. “[...] Assim, embora não existam duas árvores idênticas no mundo, a palavra 'árvore' designa um grupo de vegetais percebidos como suficientemente semelhantes para receberem a mesma designação"(Ferrari, 2010, p.152). Autores da LC desenvolveram teorias que comparam a categorização conceptual à categorização linguística. Para entender esse processo, resgatam-se aqui brevemente os paradigmas da categorização.

\section{Análise componencial sêmica}

Os linguistas formalistas trabalham com o conceito de componencialidade, que estabelece uma lista de componentes semânticos básicos para caracterizar o significado das palavras. No modelo clássico de categorização, portanto, características necessárias e suficientes são determinantes para um membro pertencer a uma determinada categoria. Isso quer dizer que, para pertencer a uma categoria, o membro deve possuir todas as características mínimas necessárias para fazer parte dessa categoria, e apenas possuí-las é suficiente para pertencer a ela.

Katz e Fodor (1963), propuseram a análise componencial sêmica (ou sistema de traços), que consiste na formalização de traços definidores do conteúdo das palavras. Com esses traços seria possível compreender o significado de uma palavra (e distingui-la de outra) por meio de sua estrutura semântica. Um exemplo dado por Ferrari (2011) é o da palavra "cavalo", que seria composto pelos traços [EQUINO], [MACHO+], [ADULTO+], enquanto "égua" seria definida por [EQUINO], [MACHO-], [ADULTO+].

A principal crítica a esse modelo é a rigidez na limitação das categorias, em que as unidades lexicais teriam valores binários (+/-), pois qualquer traço escolhido para definição de uma categoria deveria se aplicar a todos os membros daquela categoria. Em oposição a esse sistema, Wittgenstein (1979) propõe a metáfora das semelhanças familiares (family resemblances), que será vista com detalhes mais adiante, na seção "Semelhanças familiares".

\section{Conhecimento dicionarístico e conhecimento enciclopédico}

Com o desenvolvimento da abordagem mentalista da linguagem na década de 1960 e 70 (cognitivismo chomskyano), é feito um paralelismo entre conhecimento dicionarístico e nível de representação mental das palavras. Posição adotada principalmente por linguistas formalistas, sustenta a visão componencial, já explicitada no item Análise componencial sêmica deste trabalho. Nesse âmbito, o conhecimento dicionarístico contempla o significado das palavras mediante um conhecimento específico e de natureza distinta de outros conhecimentos 
(modularidade), que, como já foi dito, envolve uma visão componencial. O conhecimento enciclopédico, por sua vez, representa o conhecimento de mundo e relações do significado com o mundo propriamente dito. Vinculado ao domínio da pragmática, o conhecimento chamado enciclopédico é considerado pela Gramática Gerativa como não linguístico.

Dessa forma, a aquisição da linguagem se daria independentemente de outros módulos da mente. 0 processo de compreensão e domínio das línguas, que o falante desenvolve ao longo da vida, se daria pela Gramática Universal, uma capacidade inata do ser humano, que é ativada conforme o estímulo recebido. No entanto, o papel do contexto externo à mente do falante (relações com o próprio corpo, ambiente familiar, amigos, estímulos na escola, convívio em sociedade etc.) estaria limitado à "ativação" da Gramática Universal para as línguas em particular.

A visão alternativa adotada pela LC a respeito dos conhecimentos linguísticos e não-linguísticos citados sustenta que o conhecimento dicionarístico é uma subparte do conhecimento enciclopédico mais geral (Ferrari, 2001). Isso se justifica por dois questionamentos da LC: o primeiro refere-se à relação da semântica da palavra com o aspecto essencial do significado. A decisão de excluir algumas informações do significado central ou denotação parece arbitrária, e não é claro qual a base para a decisão de que uma determinada informação é (ou não) essencial para o significado, o que é questionado pela LC.

Outro questionamento da LC ocorre quanto à definição do significado independentemente do contexto: é considerada problemática a divisão do significado linguístico em semântica (significado independente do contexto) e pragmática (significado dependente do contexto). Fillmore (1985) e Langacker $(1987,1991)$ através da teorização das estruturas de conhecimento esquemáticas (frames) e domínios de experiência, respectivamente, reuniram evidências substanciais de que as palavras são interpretadas em relação a essas estruturas.

\section{Teorias da Linguística Cognitiva que abordam a categorização}

Entende-se que a abordagem da LC é mais inclusiva que o cognitivismo clássico, assumindo que o conhecimento linguístico advém também de experiências do falante, que ocorrem dentro e fora da mente, e que merecem ser estudadas. Essa interpretação mais ampla dá conta de conotações estereotipadas referentes aos significados das palavras, ausentes das definições de caráter composicional estipuladas no cognitivismo tradicional. Nesta seção são apresentadas as teorias que abordam a categorização.

\section{Semelhanças familiares}

Wittgenstein (1979) explora a categorização com uma metáfora das características compartilhadas entre os membros de uma família. O sistema de traços mencionado na seção "Análise componencial sêmica" é contestado pelo teórico, que propõe as semelhanças familiares, argumentando que os membros de uma categoria apresentam as mesmas relações de semelhança observadas entre os membros de uma família.

Por exemplo: um filho se parece com o pai porque tem um nariz idêntico. Esse filho tem a mesma cor do cabelo da mãe, que por sua vez tem o rosto com o mesmo formato da filha. Essa filha tem a mesma cor dos olhos do pai. Assim, segundo Wittgenstein, as aproximações semânticas se dão por familiaridade entre os membros, e não por características necessárias e suficientes, porque não necessariamente todos precisam ter o nariz de um certo jeito, o rosto de um determinado formato, o cabelo ou os olhos com uma única cor. Os irmãos são parecidos por características diferentes que herdaram dos pais, por isso todos se parecem mesmo que não haja uma característica única que seja compartilhada por todos da família.

Dessa forma, certos membros de uma mesma categoria podem, em alguns casos, não compartilhar nenhuma característica entre si e mesmo assim serem semelhantes. No exemplo citado, a filha tem o formato do 
rosto da mãe e a cor dos olhos do pai. O filho tem a cor do cabelo da mãe e o nariz do pai. Assim, "[...] não há traço compartilhado por todos os membros da família, mas um conjunto de traços que permite compartilhamentos parciais, de modo análogo, não há um traço definidor das categorias em geral" (Ferrari, 2011, p.34). Eles podem não compartilhar nenhuma característica específica entre si, mas é a semelhança com os outros membros da família (pai e mãe) que os torna parecidos e membros dessa categoria.

\section{Semântica de Frames}

Uma das abordagens possíveis para subsidiar a modelagem conceitual é a Semântica de Frames, uma teoria linguística posicionada sob o paradigma teórico da Linguística Cognitiva. Proposta por Fillmore em 1975, a Semântica de Frames considera os fatores culturais e o contexto em que as ações ocorrem para descrição das estruturas cognitivas envolvidas em um evento, tendo seu apogeu na materialização da FrameNet (léxico computacional baseado na Semântica de Frames), em trabalho publicado em 1982 (Fillmore, 1982).

Em contraste com o sistema de traços, a Semântica de Frames preconiza que o significado das palavras é ancorado nas experiências e instituições humanas. Assim, considera o contexto e os fatores culturais em que as ações ocorrem para descrição das estruturas cognitivas envolvidas em um evento. De acordo com Moreira e Salomão (2012, p.491), frames são "[...] estruturas conceituais estabelecidas na memória permanente, frutos de nossa interação com o mundo e da consolidação de nossa experiência diária". Dessa forma, pode-se dizer que se trata de uma teoria que considera as experiências vividas pelos indivíduos e o seu reflexo nos processos de interpretação de um modo geral, razão pela qual o contexto em que um evento ocorre é fundamental para a compreensão do seu sentido correto ou mais adequado. É preciso lembrar que considerar as experiências dos indivíduos implica aceitar que o contexto social e cultural vai interferir em sua interpretação de mundo e na forma como eles compreendem o significado das palavras - dito de outra forma, significa considerar o conhecimento enciclopédico dos falantes em relação às palavras e ao sentido que elas evocam. Por isso, um mesmo evento pode ser interpretado de forma diferente por pessoas de contextos sociais e culturais diferentes.

Petruck (1996, p.1) apresenta outra definição de frame como "[...] qualquer sistema de conceitos relacionados de forma que, para entender qualquer um dos conceitos, é necessário compreender o sistema inteiro [...]". Ou seja, para que se possa entender uma parte, é preciso entender o todo em que o conceito está inserido.

Fillmore (1982) usa como exemplo a expressão Bachelor (solteirão): segundo o autor, a definição por meio de traços, composta por [MACHO+], [ADULTO+], [CASADO-], não daria conta do significado da palavra. Porque, por exemplo, um padre não pode ser considerado solteirão, uma vez que o celibato não o coloca em uma categoria de "possível candidato ao casamento". Também um "jovem adulto" de dezoito anos não pode ser considerado solteirão, pois a expectativa de idade ideal para casar está apenas começando. Assim, o autor sugere que, na verdade, a definição do termo requer o acesso a um domínio cognitivo específico, que ele chamou de frame. Nas palavras de Fillmore (1982, p.111, tradução nossa)², o conceito de frame define-se da seguinte forma:

[...] qualquer sistema de conceitos relacionados de tal forma que para entender qualquer um deles você deve entender a estrutura como um todo na qual ele se encontra; quando uma das 'coisas' desta estrutura é introduzida em um texto, ou em uma conversa, todas as outras são automaticamente disponibilizadas.

Pode-se dizer que o frame refere-se à estrutura de conceitos relacionados que se ativam mutuamente, compondo um determinado contexto que é cognitivamente acionado a partir da palavra ou expressão à qual o frame se refere. Ou seja, as palavras fazem sentido porque evocam o conhecimento de mundo que é organizado

\footnotetext{
$\mathbf{2}$ "[...] any system of concepts related in such a way that to understand any one of them you have to understand the whole structure in which it fits, when one of the things in such a structure is introduced into a texture into a conversation, all of the others are automatically made available" (Fillmore, 1982, p.111).
} 
por meio de uma estrutura cognitiva (frame). O frame reúne, portanto, conhecimento compartilhado em relação a expectativas socioculturais - no caso do "solteirão", expectativas referentes à idade apropriada para o casamento.

No artigo citado, Fillmore afirma, com exemplos de contextos especializados, que o processo de entendimento de um texto envolve não só recuperar ou perceber os frames evocados pelo conteúdo lexical do texto, como também reunir esse tipo de conhecimento esquemático em alguma espécie de "visualização" do "mundo" do texto - o que evidencia uma forte conexão entre semântica lexical e semântica textual (processo de compreensão de texto). Afirma ainda que a visualização do mundo do texto pelo intérprete demonstra a perspectiva e a história daquele mundo -, que pode ser uma história mais larga que a história da narrativa em andamento no momento da interação.

Para Fillmore (1985), a Semântica de Frames descreve a contribuição semântica de itens lexicais e construções gramaticais para explicar o processo de construção da interpretação de um texto e de suas partes. Para o autor, as unidades e categorias de linguagem servem aos propósitos de comunicação e compreensão, ou seja, existem para ajudar o falante a compreender o sentido das "coisas" em um processo de comunicação.

Croft e Cruse (2004, p.8) explicam que Fillmore descreve o modelo da Semântica de Frames como "[...] um modelo de semântica da compreensão ao invés de uma semântica de condições de verdade: trata-se da compreensão rica e completa que um orador pretende transmitir em um texto e que um ouvinte constrói para esse texto". Para Moreira e Salomão (2012, p.491), a grande contribuição da Semântica de Frames "[...] é propor que os significados das expressões linguísticas sejam interpretados de acordo com o frame de fundo que é evocado no momento do enunciado". Em vista disto, Croft e Cruse (2004) argumentam que muitas palavras e conceitos não podem ser compreendidos sem que se leve em consideração a intenção dos participantes das instituições sociais, culturais e comportamentais, nas quais a ação, o estado ou a coisa está situada. Para os autores, um exemplo é o conceito de vegetariano, que só fará sentido em um frame de uma cultura em que comer carne é comum.

\section{Categorias radiais}

No livro "Women, Fire and Dangerous Things", Lakoff (1987) trabalha os modelos cognitivos idealizados, principal tese do livro. O autor afirma que cada modelo cognitivo idealizado (Idealized Cognitive Model - ICM) é uma estrutura complexa, composta por estrutura proposicional (proposta por Fillmore na Semântica de Frames), estrutura imagético-esquemática (da Gramática Cognitiva de Langacker), mapeamentos metafóricos e mapeamentos metonímicos (Lakoff e Johnson).

No capítulo 6 do livro (Lakoff, 1987), as categorias radiais são extensamente exploradas. A estrutura radial de uma categoria é formada por uma subcategoria central - definida por um conjunto de modelos cognitivos convergentes -, e por extensões periféricas, que não são instâncias especializadas (mais específicas) da subcategoria central, mas sim variações da mesma. As extensões da subcategoria central são "motivadas".

Para explicar as estruturas radiais, Lakoff (1987) exemplifica vários tipos de mãe e afirma que não há característica geral na categoria "mãe" que possa gerar "tipos de mães". Esses tipos são culturamente aprendidos e variam de cultura para cultura. A categoria mãe possui uma estrutura radial: há um caso central e variações convencionais que não podem ser previstas por regras gerais. Estão excluídas das estruturas radiais as categorias geradas por casos centrais adicionados de princípios gerais, assim como categorias onde o caso central é apenas mais geral (possui menos características) do que os casos periféricos. As estruturas radiais precisam ser constituídas de casos cujas variações são convencionais e devem ser aprendidas.

No subtítulo "mulheres, fogo e coisas perigosas", que dá nome ao livro, Lakoff apresenta, com exemplos de um estudo realizado por Dixon em 1982 sobre uma língua aborígene australiana (Dyirbal), princípios que o segundo descobriu e o primeiro tratou de cunhar: o Princípio do domínio baseado na experiência; o Princípio do mito e crença; e o Princípio da propriedade importante. Suas definições são citadas a seguir: 
- Princípio do domínio baseado na experiência: "existe um domínio baseado na experiência associada com A, então é natural que as entidades nesse domínio estejam na mesma categoria que A" (Lakoff, 1987, p.93);

- Princípio do mito e crença: "se algum substantivo tem característica $X$ (com base na qual se espera a sua composição de classe a ser decidida), mas é, através da crença ou mito, conectado com a característica Y, então geralmente ele vai pertencer à classe correspondente a Y e não correspondente à X" (Lakoff, 1987, p.94);

- Princípio da propriedade importante "Se um subconjunto de substantivos tiver alguma propriedade importante particular que o restante do conjunto não tenha, os membros do subconjunto podem ser atribuídos a uma classe diferente do resto do conjunto para "marcar" essa propriedade; a propriedade importante é mais frequentemente 'nociva' [ou perigo]" (Lakoff, 1987, p.94, tradução nossa) ${ }^{\mathbf{3}}$.

Os princípios gerais de classificação dessa cultura aborígene, na visão de Dixon, são: centralidade; encadeamento; domínios experimentais; modelos idealizados; conhecimento específico; outros; nenhuma propriedade em comum; motivação. A teoria da categorização faz predições sobre o que sistemas de categorias humanas podem e não podem ser, mas não prevê exatamente o que estará em determinada categoria numa cultura ou língua.

A partir da análise da língua aborígene Dyirbal, Lakoff aponta os itens que são necessários para descrever um modelo básico de sistema linguístico humano: um modelo básico, contendo as categorias presentes no sistema; uma especificação de quais subcategorias são centrais ou mais típicas (no caso de subcategorias estruturadas); um modelo básico de oposição, que estrutura os centros em relação um ao outro (contrastes); uma especificação de princípios de encadeamento; e uma lista restrita de exceções, distribuídas de acordo com o modelo básico de oposição.

Lakoff (1987) examina também o classificador "hon" na língua japonesa, mais comumente utilizado para classificar objetos longos e finos. Os melhores exemplos são rígidos, longos e finos, mas o uso de hon também pode ser estendido para casos menos representativos, mas de alguma forma ligados à característica inicial. $\mathrm{O}$ relacionamento entre, por exemplo, a forma do bastão de baseball e o desenho da trajetória da bola rebatida é um relacionamento comum entre esquemas visuais que formam a base para a extensão de uma categoria a partir de um exemplo central para um caso periférico, o que ele chama de "esquema visual das transformações". A partir dos exemplos do texto, Lakoff delineia algumas conclusões: (i) a direção da extensão de hon parece ir de objetos concretos para outras coisas, como objetivo de um jogo ou trajetória de uma bola; (ii) é necessária uma teoria de motivações para a extensão de uma categoria, explicitada através de, entre outras coisas, um "esquema visual das transformações" e metonímias conceituais; (iii) o relacionamento entre o bastão e a jogada se dá através da "transformação esquema-visual" e uma metonímia - sendo inadequada a teoria clássica, que requer que a categorização seja baseada em propriedades comuns; (iv) as aplicações de hon para as extensões podem fazer sentido, mas não são previsíveis; são convencionadas e motivadas (não arbitrárias). Por esse motivo, a visão generativa - de que tudo deve ser previsível ou arbitrário -, não se aplica.

Para Lakoff (1987), é necessário aos estudiosos de sistemas de classificação linguística entender os critérios de adequação, por meio dos quais é possível encontrar a "motivação" (mesmo sutil) de cada extensão da categoria, de modo que atribuir arbitrariedade deve ser o último recurso. O autor elenca então as transformações esquema-visuais, imagens mentais convencionais e metonímia como elementos da categorização, bem como acrescenta a metáfora (com o exemplo do uso de hon para telefones).

Para discutir se os sistemas classificatórios são apenas palavras ou categorias mentais, Lakoff (1987) aponta os seguintes princípios de organização linguística: membros centrais e periféricos; objetos de nível básico no centro; imagens mentais convencionadas; conhecimento sobre imagens mentais convencionadas; transformações

\footnotetext{
3 "If a subset of nouns has some particular important property that the rest of the set does not have, then the members of the subset may be assigned to a different class from the rest of the set to 'mark' this property; the important property is most often 'harmfulness"' (Lakoff, 1987, p.94).
} 
esquema-visuais; metonímia aplicada a imagens mentais; metonímia aplicada a domínios de experiência; e metáforas (que mapeiam domínios dentro de outros domínios). Depois, contrasta categorias cognitivas com meras relíquias históricas, argumentando que os sistemas classificatórios não são relíquias histórias, pois, para serem adotadas no sistema (convencionadas), precisam fazer sentido para os falantes que estão tornando as inovações parte do seu sistema linguístico, o que é um sistema cognitivo.

Lakoff afirma, com base em argumentos de Denny (1976), que o sistema conceitual é dependente da experiência física e cultural - ou, pelo menos, intimamente ligado a ela -, refutando a visão clássica de que os conceitos são abstratos e separados da experiência humana.

\section{Teoria dos Protótipos}

O modelo clássico de categorização foi questionado também na Psicologia Cognitiva, por Rosch (1973, 1978). O novo modelo de categorização proposto, amparado na antropologia e psicologia, é conhecido como Teoria dos Protótipos. Para Rosh, tradicionalmente, as pesquisas cognitivas eram trabalhadas a partir das categorias aristotélicas, as quais se caracterizavam como entidades do tipo lógico-matemático cujos membros possuíam o mesmo estatuto e não eram diferenciados entre si. Nesse sentido, a ideia de protótipo vai contra o princípio aristotélico de categorias lógicas e defende que, no interior de uma categoria conceitual, existem representantes mais nucleares e menos nucleares.

Os protótipos são membros que possuem todas as características de determinada categoria, ou o que se pode chamar de "melhor exemplo" da mesma. As categorias possuem membros centrais e membros periféricos: os membros centrais possuem suficiente similaridade ao protótipo, enquanto os periféricos possuem poucos traços em comum com o núcleo categorial. Tradicionalmente, os efeitos mais estudados são a assimetria entre categorias e as gradações de distância em relação ao "melhor exemplo". "A Teoria dos Protótipos prevê que as categorias se organizam, de modo geral, em torno de um núcleo prototípico. Embora o protótipo se caracterize por possuir todos os traços definidores de uma determinada categoria, membros que apresentam um número menor de traços definidores também podem ser incluídos" (Ferrari, 2010, p.152).

Um exemplo disso é a categoria AVE, na qual um membro nuclear poderia ser SABIÁ, ao passo que PINGUIM seria um membro mais periférico (Finatto, 2001). Ou seja, Rosch continuou a aceitar o papel das características ou "atributos" na caracterização de categorias, demonstrando que estas têm uma estrutura interna, no sentido de que alguns membros podem ser "melhores" ou "mais representativos", servindo de exemplo para uma determinada categoria, ou seja, apresentando um caráter mais prototípico (Taylor, 2008).

Para Taylor (2008), outra descoberta importante de Rosch foi que muitas categorias não tinham limites claros. Suas descobertas foram empregadas rapidamente no estudo dos significados das palavras e provaram ser especialmente frutíferas na investigação da polissemia. A Teoria dos Protótipos também tem aplicações no estudo das categorias da linguagem em si e inclui as categorias lexicais (substantivo, adjetivo etc.), as construções sintáticas e, até mesmo, as categorias fonológicas, tais como o fonema.

Segundo Duque (2001), uma pesquisa pioneira que auxiliou tanto no entendimento da noção de protótipo quanto para a linguística cognitiva em geral, foi o estudo das cores básicas. Para o autor, "[...] os resultados contradizem a hipótese estruturalista da arbitrariedade das categorias linguísticas, assim como a concepção de sua organização em traços essenciais" (Duque, 2001, p.97).

Para Rosch (1973), as categorias de cores são processadas pela mente humana em termos de sua estrutura interna; elas parecem ser representadas na cognição não como um conjunto de características com critérios e limites claros, mas, sim, em termos de um protótipo (melhores exemplos) da categoria, rodeado por outras cores com menor semelhança com o protótipo e com menor grau de adesão (Taylor, 2008). Duque (2001) explica que as categorias de cor têm centro e periferia e que, em consequência, seus membros não possuem o mesmo status 
(existem roxos melhores, verdes melhores, amarelos melhores etc.). Na visão dos autores, as categorias das cores ou o nome dado às cores focais (básicas) não é arbitrário, mas prototípico.

Riemer (2010) explica que os Modelos Cognitivos Idealizados (Idealized Cognitive Model - ICM) auxiliam a compreender a Teoria dos Protótipos, pois, nessa teoria, podem-se ter exemplares mais periféricos ou mais centrais de uma categoria. O ICM de "solteiro" de uma determinada pessoa, por exemplo, vai balizar sua interpretação em relação ao conceito de solteiro. O contato com exemplares de uma categoria é necessário para a identificação dos traços centrais dessa categoria. Logo, a natureza idealizada do ICM causa os efeitos prototípicos; em outros termos, saber o significado de uma palavra significa ativar uma estrutura cognitiva subjacente. Iyer e D’Ambrosio (2012) explicam que grande parte do conhecimento é organizada com base em exemplos típicos, a partir dos quais são feitas inferências e generalizações. O homem tende a usar os casos típicos para fazer generalizações, e não o contrário. Uma palavra é o ponto de entrada para uma região da estrutura conceitual do falante. Quando alguém se refere ao ICM "cabeça", não significa que tudo que conhece sobre cabeça será imediatamente evocado; a cada nova situação abre-se um novo significado, devido às possibilidades oferecidas pelo conhecimento enciclopédico de cada pessoa. As diferentes facetas de "cabeça" (um ICM único) podem ser relevantes em diferentes contextos.

Segundo essa teoria, a perspectiva corporal de uma pessoa (seu corpo no mundo) repercute na linguagem. As categorias cognitivas (frente, trás, lado) influenciam na forma como cada um entende o espaço a sua volta. Dessa forma, os atributos que eram periféricos podem assumir um lugar mais central em função da cultura envolvida (Riemer, 2010).

lyer (1995) destaca a medida probabilística, chamada "sinal de validação", utilizada por Rosch em seu estudo empírico das categorias, como uma possível contribuição para a atividade de classificação e indexação de assuntos. O sinal de validação pode ser observado quando algumas características de conceitos atuam como indicadores de uma categoria, em razão de sua frequente associação com ele. Dessa forma, a validade de uma categoria aumenta com o número de características distintivas e, inversamente, diminui com o aumento de características comuns partilhadas com outras categorias (lyer, 1995).

\section{Barreiras categoriais fluidas}

Rosch (1973, 1978) realizou estudos clássicos sobre os "bons exemplos" das categorias "arma", "ave", "brinquedo", "esporte", "ferramenta", "fruta", "legume", "mobília" e "veículo". O objetivo era demonstrar que os tipos de entidade são organizados em termos de categorias prototípicas cujos limites não são nítidos. Por sua vez, Labov, em 1973 e 1978, objetivando testar a falta de precisão dos limites categoriais, desenvolveu vários experimentos envolvendo xícaras e objetos similares.

Com base nos resultados desses estudos empíricos, Ferrari (2011, p.39) conclui que:

(i) as categorias não representam divisões arbitrárias de entidades do mundo, mas surgem baseadas em capacidades cognitivas da mente humana; (ii) categorias de cores, formas, mas também organismos e objetos concretos, são ancoradas em protótipos conceitualmente salientes que desempenham papel crucial na formação dessas categorias; e (iii) as fronteiras das categorias cognitivas são imprecisas, de modo que categorias vizinhas não são separadas por limites rígidos, mas há uma zona de intersecção.

A limitação precisa das categorias, portanto, ocorre apenas na virtualidade. A organização mental que se faz é diferente da segmentação categorial clássica, não tão assertiva e objetiva como se supunha.

\section{Integrando as teorias da LC ao planejamento de SKOS}

Conforme mencionado anteriormente, o objetivo deste estudo é levantar algumas questões que circundam o âmbito da Organização do Conhecimento há alguns anos e discutir acerca de aspectos basilares da classificação. 
Entende-se que essa discussão pode oferecer alternativas que prestem suporte à resolução gradual de alguns problemas quanto à diferença entre a linguagem dos usuários e a linguagem dos responsáveis pela elaboração de SKOS.

A Semântica Formal tem sido utilizada na estruturação dos metadados para os SKOS. Isso se dá pela necessidade intrínseca de que se formalize a linguagem utilizada, para viabilizar a comunicação entre sistemas automatizados. Por outro lado, acredita-se que a Linguística Cognitiva dá subsídios teóricos para analisar um domínio e apreendê-lo em toda sua complexidade de relações, o que é caro à Organização do Conhecimento.

Na prática, possibilita que o responsável pela modelagem de um domínio possa identificar mais claramente as características e/ou relações existentes entre os conceitos do mesmo e de que forma elas podem afetar a categorização. Isso possibilita o planejamento da explicitação dessas relações, o que resultará na formalização tanto de características, quanto de contexto e de relacionamentos que vão além das clássicas relações hierárquicas, associativas e de equivalência dos tesauros tradicionais, por exemplo. Quanto mais explícitas são as relações entre os conceitos, mais forte semanticamente será o produto obtido.

A Linguística Cognitiva demonstra que as categorias tendem mais ao fluido do que ao dicotômico, conforme as diversas teorias apresentadas ao longo deste artigo, e especialmente na seção "Barreiras categoriais fluidas". A análise de um domínio à luz dos pressupostos teóricos da LC permite a identificação de exceções e características do próprio domínio que são relevantes para sua modelagem. Essa premissa reforça que nada pode ser analisado fora do seu contexto, porque algumas semelhanças somente são identificadas a partir do universo em que ocorrem, como foi explicado na seção "Semelhanças Familiares".

Transpondo essa problemática para a aplicação em SKOS, pode-se afirmar que não são apenas as características intrínsecas das entidades que dariam conta de associar membros de uma determinada categoria, mas também as relações em comum. As semelhanças familiares são um exemplo de que os membros pertencem a um mesmo grupo não por terem características compartilhadas, mas porque compartilham relações e domínio.

Até agora essas exceções vinham sendo pouco exploradas por estarem ainda ancoradas em uma metodologia clássica, que não dá conta da complexidade dos universos que se quer representar. Um exemplo dessa fragilidade é o Sistema de traços (+/-), presente na Semântica Formal, que reduz a complexidade do mundo às características necessárias e suficientes para uma entidade pertencer a uma categoria, o que os estudos em LC apontam como inadequado para tratar de casos menos prototípicos. No cenário atual já existe suporte teórico suficiente para possibilitar a inclusão dessas especificidades no processo categorização, o que enriquece a modelagem de domínio.

Contudo, não se pode escapar da formalização de todos os aspectos conceituais (a saber: relações, atributos, cenários, contexto de aplicação, dentre outros) que circundam a elaboração de SKOS, visto que os computadores demandam a formalização para efetivar a comunicação entre os sistemas. Assim, apresentam-se a seguir algumas formas para viabilizar a integração dessa proposta utilizando as plataformas atuais de modelagem de domínio.

Ao representar as relações associativas em SKOS, pode-se aplicar a concepção de frame, visto que este evoca o contexto de ocorrência dos fenômenos. Embora a relação associativa já existisse nos tesauros, através da LC é possível apreender analiticamente o tipo específico de relação associativa que está estabelecido, para então explicitá-la formalmente. Por exemplo, no contexto de análise da Dengue, que é uma doença, pode-se identificar qual o agente causador, no caso o mosquito Aedes Aegypti, assim como os sintomas e outras doenças causadas por ele. Num tesauro tradicional, essas relações estariam descritas como Termo Relacionado (TR), reduzindo a um único rótulo as relações doença-agente causador, doença-sintomas e doença-doenças. Porém, é possível explicitar essas relações especificando o tipo de relação associativa que de fato ocorre, conforme já sugere a própria norma ISO 25.964 (2011). Portanto será necessário criar rótulos mais específicos para essas relações.

A Teoria dos Protótipos mostra-se bastante produtiva para estabelecer a estrutura hierárquica em SKOS, visto que, ao contrário do método indutivo (top-down), a análise dos atributos que constituem os elementos 
possibilita a identificação dos membros prototípicos, e por oposição, dos membros periféricos de uma determinada categoria. Os membros que compartilham um número maior de atributos entre si tendem a ser mais centrais e, portanto, mais prototípicos do que os membros que compartilham menos características com o grupo. Estes, considerados membros mais periféricos, podem também possuir um atributo muito diferente dos demais, mesmo compartilhando muitas características, conforme ocorre no exemplo de "ave" e "pinguim", já mencionado na seção "Teoria dos Protótipos".

Ao representar uma categoria, tradicionalmente são destacados apenas os seus atributos mais representativos, ignorando as especificidades. Destaca-se aqui que sempre vão existir membros mais prototípicos e que representam melhor a classe, mas não se podem negligenciar os mais periféricos apenas por compartilharem poucos atributos ou possuírem alguma característica distinta dos demais. Para que isso seja possível, dois caminhos são viáveis: um deles é ampliando o número de atributos nas classes (incluindo, portanto, atributos de membros menos prototípicos) e não restringindo a participação dos membros quanto ao cumprimento desses requisitos. O segundo é construir uma tipologia de hierarquia considerando subclasses que agrupem apenas os membros mais próximos (com mais características em comum), o que possibilita que se criem categorias mais específicas e representativas do que apenas uma grande classe genérica.

\section{Conclusão}

Neste artigo foram apresentadas algumas teorias importantes da Linguística Cognitiva, explorando aspectos da categorização que compõem o seu referencial teórico, sem, no entanto, esgotá-los. Também não era compromisso deste estudo referenciar todo o arcabouço teórico da LC, motivo pelo qual foram escolhidas algumas das teorias que melhor parecem se adequar para elucidar a questão da categorização e melhor se aplicam à prática de modelagem conceitual e construção de SKOS. A riqueza e sofisticação da teorização no campo da Linguística Cognitiva podem servir de incentivo para o leitor aprofundar os conhecimentos abordados neste ensaio de maneira mais pontual. Convém destacar, como convite a futuras leituras, os teóricos Langacker, Talmy, Cruse e Fauconnier.

Viu-se, ao longo da revisão teórica, que a categorização é um processo bastante complexo e sofisticado da mente humana. Foi observado que o frame reúne conhecimento compartilhado quanto às expectativas socioculturais relacionadas ao item lexical, o que possibilita sua correta interpretação. Foram exploradas as aproximações semânticas, que se dão por familiaridade entre os membros, e não por características necessárias e suficientes. Assim, certos membros de uma mesma categoria podem, em alguns casos, não compartilhar nenhuma característica entre si e mesmo assim ser semelhantes. Estudou-se a Teoria de Protótipos, que apresenta importantes contribuições para a organização da informação, especificamente para a elaboração de tesauros, devido ao respaldo teórico que oferece para compreender a forma como as pessoas realizam a categorização das coisas no mundo. Esta pesquisa é relevante, sobretudo, pelo fato de demonstrar na prática que os conceitos são categorizados uns em relação aos outros e que os aspectos culturais influenciam as pessoas ao estabelecerem categorias, razão pela qual o processo de classificação do conhecimento é difuso e complexo.

Com os estudos aqui apresentados é possível concluir que os sistemas classificatórios refletem aspectos experimentais, imaginativos e ecológicos da mente. Não há limites claros entre as categorias: elas têm margens difusas e continuam tendo um elenco de características, mas esse elenco vai aumentar e diminuir conforme a interpretação que se quer dar dentro de um contexto específico. Entende-se que tanto os conceitos quanto a categorização podem ser construídos e, por isso, sofrer alterações culturais, além de servirem de diferentes formas em determinados contextos. Assim, a categorização não é algo incontestável tampouco universal.

No caso da elaboração de tesauros e ontologias, em especial na modelagem da rede de conceitos do domínio, esse entendimento sobre a categorização é fundamental, tendo em vista os objetivos almejados e o 
público a ser alcançado. Ee es essa característica que explica por que a interoperabilidade de SKOS é um grande desafio, muitas vezes intransponível, uma vez que nem sempre os conceitos de um domínio são de fato compartilhados integralmente entre todos os usuários de um SKOS.

\section{Colaboradores}

Todos os autores contribuíram na concepção e desenho do estudo, análise de dados e redação final.

\section{Referências}

Bräscher, M.; Café, L. Organização da informação ou organização do conhecimento? In: Encontro Nacional de Pesquisa em Ciência da Informação, 9., 2008, São Paulo. Anais... São Paulo: Ancib, 2008.

Croft, W:; Cruse, D. A. Cognitivelinguistics. New York: Cambridge University Press, 2004.

Denny, J. P. What are Noun Classifiers Good For? In: Papers from the Twelfth Regional Meeting, Chicago Linguistic Society. Chicago: Chicago Linguistic Society, 1976. p. 122-132.

Duque, P. H. Teoria dos protótipos, categoria e sentido lexical: primeira parte. Revista Philologus, ano 7, n. 21, 2001. Disponível em: <http://www.filologia.org.br/rph/ANO07/21/010.pdf>. Acesso em: 2 ago. 2011.

Ferrari, L. V. A Linguística cognitiva e o realismo corporificado: implicações filosóficas e psicológicas. Veredas, v. 5, n. 2, p. 23-29, 2001.

Ferrari, L. V. Modelos de gramática em linguística cognitiva: princípios convergentes e perspectivas complementares. Cadernos de Letras da UFF - Dossiê: Letras e Cognição, n. 41, p. 149-165, 2010.

Ferrari, L. V. Introdução à linguística cognitiva. São Paulo: Contexto, 2011.

Fillmore, C. J. Frame semantics. In: Linguistics in the Morning Calm: Selected papers from SICOL - 1981. Seoul: Hanshin Publishing Company, 1982. p. 111-138.

Fillmore, C. J. Frames and the semantics of understanding. Quaderni di Semantica, v. 5, n. 2, p. 222-254, 1985.

Finatto, M. J. B. Terminologia e ciência cognitiva. In: Krieger, M. G.; Maciel, A. M. B. (Org.). Temas de terminologia. Porto Alegre: Editora UFRGS, 2001. p. 141-149.

Fiorin, J. L. Introdução à linguística I. São Paulo: Contexto, 2002. International Organization for Standardization (ISO). ISO 25.964-1. Information and documentation - Thesauri and interoperability with other vocabularies - Part 1: Thesauri for information retrieval. Geneva: ISO, 2011.

Iyer, H. Classificatory structures: Concepts, relations and representations. Frankfurt: Index Verlag, 1995.
Iyer, H.; D'Ambrosio, A. Archetypes, idealized cognitive model and prototype effect: A discussion of images and cognition in categorization. Advances in Knowledge Organization, v. 13, p. 236-241, 2012.

Katz, J.; Fodor, J. A. The structure of a semantic theory. Language, v. 39, n. 2, p. 170-210, 1963.

Lakoff, G. Women, fire and dangerous things: What categories reveal about the mind. Chicago: University of Chicago Press, 1987.

Langacker, R. Foundations of cognitive grammar. Standford: Stanford University Press, 1987. (Theoretical prerequisites, v. 1).

Langacker, R. Foundations of cognitive grammar. Standford: Stanford University Press, 1991. (Descriptive Applications, v. 2).

Moreira, A.; Salomao, M. M. Análise ontológica aplicada ao desenvolvimento de Frames. Alfa: Revista de Linguística, v. 56, n. 2, p. 491-521, 2012. Disponivel em: <http://www. scielo.br/scielo.php?script=sci_arttext\&pid=\$1981-5794 $2012000200007 \&$ lng=en\&nrm=iso $>$. Acesso em: 2 out. 2013.

Petruck, M. R. L. Frame semantics: Handbook of pragmatics. Amsterdam: Benjamins, 1996.

Riemer, N. Introducing semantics. Cambridge: Cambridge University Press, 2010.

Rosch, E. Principles of categorization. In: Rosch, E.; Lloyd, B. (Org.). Cognition and categorization. Hillsdale: Erlbaum, 1978.

Silva, A. S. A Linguística cognitiva: uma breve introdução a um novo paradigma em linguística. Revista Portuguesa de Humanidades, v. 1, n. 1-2, p. 59-101, 1997.

Silva, A. S.; Batoréo, H. J. Gramática cognitiva: estruturação conceptual, arquitectura e aplicações. In: Brito, A. M. (Org.). Gramática: história, teorias, aplicações. Porto: Universidade do Porto, 2010. Disponível em: <http://ler.letras.up.pt/uploads/ ficheiros/8319.pdf >. Acesso em: 25 jul. 2014.

Taylor, J. R. Prototypes in cognitive linguistics. In: Robinson, P.; Ellis, N. C. (Org.). Handbook of cognitive linguistics and second language acquisition. New York: Routledge, 2008. p. 39-65.

Wittgenstein, L. Investigações filosóficas. São Paulo: Nova Cultural, 1979. (Os Pensadores). 